\title{
A UTILIZAÇÃO DE PRESSUPOSTOS DO EDUCAR PELA PESQUISA NA ORGANIZAÇÃO E OFERTA DE UM CURSO DE EXTENSÃO PARA A FORMAÇÃO CONTINUADA DE PROFESSORES DE CIÊNCIAS
}

\section{EMPLOYING THE EDUCATING THROUGH RESEARCH ASSUMPTIONS INT THE ORGANIZATION AND OFFER OF AN EXTENSION COURSE FOR THE CONTINUOUS DEVELOPMENT OF SCIENCE TEACHERS}

\author{
Bárbara Gonçalves Fenille Velasco* \\ ORCID: https://orcid.org/0000-0003-2574-2572 \\ Alexandre Tadachi Morey** \\ ORCID: https://orcid.org/0000-0001-9975-4627 \\ Daniela Rodrigues da Silva*** \\ ORCID: https://orcid.org/0000-0002-8328-6627
}

RESUMO:

O presente trabalho apresenta a análise de resultados de um curso de extensão realizado no IFRS - Campus Canoas para formação continuada de professores de ciências da educação básica. O curso foi organizado a partir de pressupostos do educar pela pesquisa, de modo que cada professor em formação elaborou um questionamento reconstrutivo e, a partir desse questionamento, que contemplava alguma motivação individual relacionada às vivências profissionais, organizou um planejamento para ser desenvolvido no contexto da sala de aula. A formação continuada abordou metodologias oriundas das vivências dos professores formadores durante suas pesquisas e experiências profissionais. Sendo um estudo de caso organizado com pressupostos qualitativos, o presente artigo utilizou a análise de conteúdos para a categorização dos resultados produzidos pelos professores, tanto na elaboração e reelaboração do questionamento reconstrutivo quanto na crítica ao planejamento dos pares, como estratégia para o exercício da criação própria e para a construção de conhecimentos.

Palavras-chave: Formação de professores; Ensino de ciências; Educar pela pesquisa; Educação básica.

\section{ABSTRACT:}

This work presents the analysis of the results of an extension course held at IFRS - Campus Canoas aiming at the continuous education of science teachers in basic education. The course was organized based on the assumptions of educating through research, thus each teacher taking part in the course elaborated a reconstructive questioning, and from that questioning, which contemplated some individual motivation related to the participants' professional experiences, a plan was devised to be developed in the classroom context. The continuous education course approached methodologies originated from the teacher educators' experiences during their research and professional practice. This is a qualitative case study, which used content analysis to categorize the results produced by the teachers in the elaboration and re-elaboration of the reconstructive questioning and the critique to their peers' plans as a strategy for the exercise of the participants' authorship and construction of knowledge.

Keywords: Teacher training; Teaching science; Educating through research; Basic education.

* Licenciatura em Matemática. Instituto Federal do Rio Grande do Sul (IFRS), Campus Canoas - RS, Brasil. E-mail: barbaragfv@gmail.com ** Professor do Instituto Federal do Rio Grande do Sul (IFRS), Campus Canoas - RS, Brasil. E-mail: alexandre.morey@canoas.ifrs.edu.br *** Professora do Instituto Federal do Rio Grande do Sul (IFRS), Campus Canoas - RS, Brasil. E-mail: daniela.silva@canoas.ifrs.edu.br 


\section{Introdução}

Neste trabalho serão discutidos resultados de um curso de formação de professores de ciências oferecido no Instituto Federal de Educação, Ciência e Tecnologia do Rio Grande do Sul (IFRS) - Campus Canoas. O curso foi organizado considerando os pressupostos do educar pela pesquisa, segundo Demo $(2011,2015)$ e Galiazzi e Moraes (2002), e teve por objetivo oferecer um espaço para formação continuada para docentes da área de ciências, de instituições de ensino da rede pública de Canoas e região.

A oferta de um curso para a formação de professores de ciências atende a uma das finalidades e características previstas na lei que cria os Institutos Federais de Educação e Tecnologia (lei 11.892), que indica que essas instituições devem qualificar-se como centros de referência no apoio à oferta do ensino de ciências nas instituições das redes públicas de ensino, oferecendo capacitação técnica e atualização pedagógica aos docentes.

A ideia de estudar estratégias metodológicas diferentes daquelas em que o docente se coloca como um transmissor de conteúdos e o estudante um receptor passivo, resultou do trabalho de pesquisa e da experiência profissional dos professores formadores (MEDEIROS et al, 2017; SCANDORIEIRO et al, 2018; SILVA, 2014; SILVA, DEL PINO, 2014; 2016). Assim, a Resolução de Problemas, a Contação de Histórias e a Aprendizagem Baseada em Problemas (Problem-Based Learning) foram estudadas de acordo com os estudos de Sakai e Lima (1996), Pozo (1998) e Pozo e Gómez Crespo (2009).

Considera-se que a escolha profissional pela docência traz consigo a possibilidade de um trabalho dialético, movido pela relação entre o saber e o fazer, característica que exige do professor a busca por formação constante. Enquanto sujeito que trabalha com o conhecimento no contexto escolar, o desafio que se coloca é: como o professor pode mobilizar diferentes saberes para que sua prática se concretize enquanto espaço de aprendizagem? Nesse contexto da prática profissional do professor, as oportunidades de formação continuada apresentam-se como espaços e tempos para a reflexão coletiva e construção de conhecimentos sobre o saber-fazer profissional, de modo que o estudo de possibilidades para a articulação de diferentes metodologias de ensino e aprendizagem, bem como a integração de áreas do conhecimento, por exemplo, permitam que o docente amplie o que aprendeu na formação inicial, ou seja, durante a graduação.

A organização do curso considerou a importância da construção de um espaço e tempo para que os professores em formação pudessem estudar e vivenciar a pesquisa como atitude cotidiana na sala de aula. Assim, o presente trabalho coloca-se como uma possibilidade de análise sobre como o educar pela pesquisa pode ser utilizado como fundamento estruturante para a organização de um curso de formação continuada para professores de ciências da educação básica. 
Dentre os pressupostos cruciais para o educar pela pesquisa, Demo (2015) indica a necessidade de fazer da pesquisa atitude cotidiana do professor e do aluno, e isso traz consigo a necessidade de desconstruir a ideia de que pesquisa é coisa especial, realizada por pessoas especiais. Essa ideia, segundo o autor, faz com que o professor pense que um pesquisador é um ser complicado, que faz coisas complicadas, que ele mesmo não estaria à altura de fazer. Já o aluno entende que a pesquisa não faz parte do seu contexto escolar, que é uma fantasia, uma extravagância (DEMO, 2015). Considerar a pesquisa como atitude cotidiana, diz respeito a compreendê-la como forma de cultivar a consciência crítica, no sentido de saber intervir na realidade de modo alternativo com base na capacidade questionadora (DEMO, 2015). Há também a dimensão da pesquisa como resultado específico, ou seja, o professor precisa alimentar o processo constante de produção própria e assim ser autor da reconstrução de seus próprios conhecimentos (DEMO, 2015, GALIAZZI; MORAES, 2002). Para tanto, a consciência da implicação entre essas duas dimensões, da pesquisa como atitude cotidiana e do compromisso formal da elaboração própria, permite que o professor se entenda como um sujeito capaz de questionar a realidade e também produzir possíveis soluções para os questionamentos levantados.

O processo de construção de conhecimentos, vivenciado no exercício da pesquisa relacionada ao saber-fazer docente, permite que o professor tenha a autonomia e a competência para, por exemplo, ser o autor do próprio material didático, de modo a ocupar um espaço em que o criar e o executar estão interligados, e se complementa enquanto atribuição de um mesmo sujeito, o professor. Demo (2011) indica que, nesse contexto, quem ensina carece pesquisar, quem pesquisa carece ensinar.

Então, qual é o papel da pesquisa na educação? A pesquisa pode ser vista tanto como princípio científico como princípio educativo, ou seja:

Pesquisa como princípio científico e educativo faz parte integrante de todo processo emancipatório, no qual se constrói o sujeito histórico autossuficiente, crítico e autocrítico, participante e capaz de reagir contra a situação de objeto e de não cultivar o outro como objeto. Pesquisa como diálogo é processo cotidiano integrante do ritmo de vida, produto e motivo de interesses sociais em confronto, base da aprendizagem que não se restrinja à mera reprodução; na acepção mais simples, pode significar conhecer, saber, informarse para sobreviver, para enfrentar a vida de modo consciente (DEMO, 2011, p. 43).

No educar pela pesquisa, o professor, como sujeito capaz de analisar o seu contexto de trabalho, estuda as estratégias mais adequadas para os seus estudantes, de modo a fomentar um ambiente onde todos possam ser ativos na construção de conhecimentos durante o processo de ensino e aprendizagem. Essa é uma das formas possíveis de pensar e viver o processo educativo, de modo que todos os envolvidos se sintam capazes para interagir e aprender. Para Camargo (2013, p. 22), a aprendizagem por meio da pesquisa "[...] pode representar a chave iniciadora para uma reeducação, fomentando a pergunta do aluno como desencadeadora, desde sua formulação até as possíveis respostas, ao aprender". 
Para Demo (2015), o educar pela pesquisa visa ao desenvolvimento da competência humana, com qualidade formal e política, encontrando no conhecimento inovador uma forma de se tornarem sujeitos críticos no mundo, ou seja, transformando o aluno, visto como objeto presente em sala de aula, para receber conhecimento, em sujeito de seu próprio saber, capaz de criticar e argumentar. Isso leva, segundo Galiazzi e Moraes (2002, p. 238), a um "processo de aprender a aprender com autonomia e criatividade". Destaca-se aqui o aprender a aprender enquanto processo de elaboração própria, em que o aluno é motivado a argumentar, refazer com linguagem própria, reescrever criticamente, elaborar seu próprio texto, formular propostas e contrapropostas, diferente do que ocorre quando há o exercício da cópia e da imitação (DEMO, 2015). Para os autores, além do aluno, o professor também passa de detentor do saber para um sujeito que promove um espaço de diálogo entre professor e aluno.

Nesse contexto, acredita-se que a formação continuada pode ser um espaço para que os professores reflitam sobre as possibilidades de vivenciar um fazer docente diferente daquele em que ele é executor de propostas elaboradas por outros sujeitos, geralmente pesquisadores distantes da realidade vivenciada na educação básica, e assim, reconstruam suas concepções a respeito do papel do professor. Sabe-se que essa reconstrução não é um processo rápido, muito pelo contrário, são várias as dificuldades vivenciadas no exercício da elaboração própria, no entanto defende-se que é um caminho que precisa ser iniciado, mesmo que de forma modesta, para que a prática da sala de aula se torne um espaço de construção coletiva.

Para Galiazzi e Moraes (2002), assumir o educar pela pesquisa implica em assumir a investigação como expediente cotidiano na atividade docente, transformando as aulas em espaço, modo e tempo de pesquisa, com o entendimento de que a pesquisa perpassa pelo questionamento, pela argumentação e pela crítica e validação dos argumentos construídos ao longo do processo.

Ainda, de acordo com os autores,

[...] partindo-se do pressuposto de que todo conhecimento e toda prática são essencialmente incompletos e passíveis de superação, a educação pela pesquisa pode ser compreendida como um ciclo dialético e recursivo que se inicia com um questionamento, seguido de tentativas de reconstruir conhecimentos e práticas pela organização e defesa de novos argumentos. Estes, comunicados e submetidos a uma comunidade crítica, serão avaliados e aperfeiçoados gradativamente (GALIAZZI; MORAES, 2002, p. 241).

Assim, como forma de experienciar esse processo de autoria na construção de uma proposta condizente com a realidade vivenciada pelos professores em formação, no contexto da educação básica, buscou-se a utilização dos fundamentos do educar pela pesquisa para um curso de formação para professores de ciências, considerando-se o questionamento reconstrutivo como uma possibilidade de olhar para problemas vivenciados pelos docentes no 
contexto da prática profissional, de modo a desencadear as etapas seguintes, em que a reflexão e o diálogo com o referencial teórico e com os colegas foram fundamentais para a construção de conhecimentos que serão apresentados ao longo deste trabalho.

\section{O contexto e os sujeitos da formação e o percurso metodológico}

O curso de extensão para formação continuada de professores de ciências ocorreu nas dependências do Campus Canoas do Instituto Federal de Educação, Ciência e Tecnologia do Rio Grande do Sul. Esse Campus foi fundado em 2007 e, atualmente, oferece cursos técnicos integrados ao ensino médio, cursos superiores e pós-graduação lato sensu. Está situado em Canoas - RS, na região metropolitana da capital Porto Alegre.

Com uma carga horária de 40 horas, distribuídas em 10 encontros (quadro 1), o curso foi ofertado gratuitamente, de março a maio de 2019, sempre às terças-feiras à tarde. O dia e turno da oferta do curso resultaram de uma consulta prévia realizada com professores das instituições públicas da região de Canoas (VELASCO; SILVA, 2018).

O curso recebeu um total de 58 inscrições. A partir de critérios relacionados à atuação profissional, 30 professores foram selecionados. Ao longo do curso, alguns professores tornaram-se infrequentes por diversos motivos, dentre eles, dificuldades nas negociações para a liberação ou compensação de horas na instituição de ensino em que exercem a docência e frustração em relação à metodologia utilizada pelo curso, pois esperavam receber exemplos de atividades experimentais para aplicarem com seus estudantes. Ao final do percurso formativo, 22 professores foram certificados (mínimo de $80 \%$ de presença), sendo esses professores os sujeitos do presente trabalho. Todos assinaram um termo de consentimento autorizando a divulgação dos resultados do curso, com a preservação da identidade dos participantes. Por isso, a menção desses professores neste estudo foi organizada com a utilização da letra $\mathrm{P}$ e um número.

O grupo de professores concluintes (22) era formado por 18 licenciados em biologia, ciências da natureza, matemática ou química, sendo que 17 já eram pós-graduados e 4 eram graduandos nas áreas de biologia ou química. Dentre eles (22), 6 não estavam trabalhando na área da educação, naquele momento, e os demais (16) eram docentes da educação básica em instituições de ensino públicas da região de Canoas. Quanto ao tempo de exercício na docência, 15 eram professores há mais de 5 anos. Essas características mostram um grupo bastante heterogêneo quanto às áreas de formação e experiências profissionais.

Os professores em formação elaboraram materiais individualmente e em grupos, dependendo da demanda de cada uma das atividades (quadro 1). Os professores que não estavam trabalhando na área da educação organizaram propostas em duplas para que todos tivessem a oportunidade de desenvolver o que foi planejado em alguma instituição de ensino. 
O presente trabalho é caracterizado como qualitativo (LUDKE; ANDRÉ, 2017) na medida em que os problemas foram estudados no ambiente em que eles ocorreram naturalmente, com riqueza de dados descritivos, dando atenção a todas as etapas do processo e não somente ao produto. Considerando o contexto dos encontros do curso de formação continuada organizado, o estudo de caso teve seus contornos bem delimitados, partindo de um interesse próprio e singular (LUDKE; ANDRÉ, 2017). Ainda, segundo Yin (2015), o estudo de caso conta com múltiplas fontes de evidências, ou seja, foram consideradas as diferentes atividades realizadas durante todo o curso para a análise dos resultados.

A proposta metodológica do curso fundamentou-se nas ideias da educação pela pesquisa como modo, tempo e espaço de qualificação da formação de professores de ciências (GALIAZZI; MORAES, 2002). A essência desse entendimento de pesquisa é o questionamento, a argumentação e a crítica e validação dos argumentos assim construídos. Desse modo, durante a formação, os professores foram convidados a serem autores das próprias propostas metodológicas, de modo a solucionarem questionamentos oriundos do exercício da prática profissional.

Para tanto, cada um dos encontros contou com dois momentos: o primeiro, em que havia a exposição dialogada de um dos fundamentos teóricos relacionados às estratégias metodológicas em estudo, com relatos de experiências da utilização dessas estratégias pelos professores formadores na prática docente, e o segundo momento, em que os professores em formação realizavam atividades que fomentaram o exercício da escrita e da autoria, objetivando a construção de elementos que pudessem contribuir com a organização de estratégias que constituiriam a proposta de ensino para responder ao questionamento inicial apresentado.

O acompanhamento de cada etapa do curso foi realizado por meio da plataforma Moodle, utilizada tanto para o compartilhamento de materiais de estudo organizados pelos professores formadores, quanto para o registro de cada uma das atividades realizadas pelos professores participantes (quadro 1).

Quadro 1 - Atividades realizadas ao longo do curso

\begin{tabular}{|c|l|l|l|}
\hline Encontro & \multicolumn{1}{|c|}{ Temas de estudo } & \multicolumn{1}{c|}{ Atividades } & \multicolumn{1}{c|}{ Objetivos } \\
\hline 1 & $\begin{array}{l}\text { Apresentação da proposta do } \\
\text { curso. }\end{array}$ & $\begin{array}{l}\text { 1 - Diagnóstico inicial. } \\
\text { da experiência profissional e } \\
\text { do questionamento como } \\
\text { elemento desencadeador para a } \\
\text { elaboração de uma proposta de } \\
\text { ensino durante a formação. }\end{array}$ & $\begin{array}{l}\text { 1- Conhecer a história forma- } \\
\text { tiva e as concepções sobre } \\
\text { ensino e aprendizagem dos } \\
\text { professores }\end{array}$ \\
$\begin{array}{l}\text { 2- Conhecer o contexto de } \\
\text { da ideia inicial para o questio- } \\
\text { namento reconstrutivo. }\end{array}$ \\
\hline
\end{tabular}




\begin{tabular}{|c|c|c|c|}
\hline 2 & $\begin{array}{l}\text { Núcleos conceituais de Pozo } \\
\text { e Gómez Crespo, a contação } \\
\text { de histórias e a resolução de } \\
\text { problemas como estratégias } \\
\text { para conhecer as teorias } \\
\text { implícitas dos estudantes nas } \\
\text { aulas de ciências. }\end{array}$ & $\begin{array}{l}3 \text { - Reelaboração do } \\
\text { questionamento } \\
\text { reconstrutivo, a partir da } \\
\text { intervenção dos professores } \\
\text { formadores com definição de } \\
\text { objetivos. } \\
4 \text { - Elaboração de uma } \\
\text { proposta para conhecer as } \\
\text { teorias implícitas dos } \\
\text { estudantes. }\end{array}$ & $\begin{array}{l}3 \text { - Definir o questionamento } \\
\text { reconstrutivo com seus prin- } \\
\text { cipais objetivos, a partir das } \\
\text { orientações indicadas pelos } \\
\text { professores formadores em } \\
\text { relação às ideias / questiona- } \\
\text { mentos propostos no encontro } \\
\text { anterior. } \\
4 \text { - Exercitar a autoria por } \\
\text { meio da elaboração de } \\
\text { estratégias para conhecer as } \\
\text { teorias implícitas dos } \\
\text { estudantes a respeito do tema } \\
\text { definido no questionamento } \\
\text { reconstrutivo. }\end{array}$ \\
\hline 3 & $\begin{array}{l}\text { Aprendizagem baseada em } \\
\text { problemas - fundamentação } \\
\text { teórica e atividade coletiva }\end{array}$ & $\begin{array}{l}5 \text { - Vivência de duas práticas } \\
\text { fundamentadas na aprendiza- } \\
\text { gem baseada em problemas. }\end{array}$ & $\begin{array}{l}5 \text { - Compreender as etapas } \\
\text { que envolvem o planeja- } \\
\text { mento e o desenvolvimento } \\
\text { de atividades estruturadas a } \\
\text { partir da aprendizagem } \\
\text { baseada em problemas. }\end{array}$ \\
\hline 4 & $\begin{array}{l}\text { Aprendizagem baseada em } \\
\text { problemas - fundamentação } \\
\text { teórica e elaboração de uma } \\
\text { proposta }\end{array}$ & $\begin{array}{l}6 \text { - Planejamento de uma } \\
\text { atividade estruturada pela } \\
\text { aprendizagem baseada em } \\
\text { problemas. }\end{array}$ & $\begin{array}{l}6 \text { - Relacionar teoria e } \\
\text { prática na elaboração de uma } \\
\text { proposta para o contexto da } \\
\text { educação básica onde os } \\
\text { professores trabalham. }\end{array}$ \\
\hline 5 & $\begin{array}{l}\text { Aprendizagem baseada em } \\
\text { problemas - reconstrução a } \\
\text { partir da crítica e fechamento } \\
\text { da proposta }\end{array}$ & $\begin{array}{l}7 \text { - Retomada do que foi } \\
\text { planejado no encontro } \\
\text { anterior com adequações a } \\
\text { partir das orientações dos } \\
\text { professores formadores. }\end{array}$ & $\begin{array}{l}7 \text { - Avaliar as fragilidades da } \\
\text { proposta elaborada no } \\
\text { encontro anterior, com a } \\
\text { reorganização da proposta. }\end{array}$ \\
\hline
\end{tabular}




\begin{tabular}{|c|c|c|c|}
\hline 6 & $\begin{array}{l}\text { Educar pela pesquisa - } \\
\text { princípios e possibilidades. }\end{array}$ & $\begin{array}{l}8 \text { - Questionário sobre o } \\
\text { tema educar pela pesquisa. } \\
9 \text { - Análise de um Objeto } \\
\text { Educacional. }\end{array}$ & $\begin{array}{l}8 \text { - Construção de argumen- } \\
\text { tos para a diferenciação entre } \\
\text { estratégias onde o professor é } \\
\text { objeto e outras em que é } \\
\text { sujeito participante de ações } \\
\text { coletivas. } \\
9 \text { - Avaliar a utilização de } \\
\text { um objeto educacional como } \\
\text { modo de conhecer as teorias } \\
\text { implícitas dos estudantes, } \\
\text { assim como estratégia para o } \\
\text { estudo de conceitos } \\
\text { fundamentais das ciências e } \\
\text { da química. }\end{array}$ \\
\hline 7 & $\begin{array}{l}\text { Planejamento de uma } \\
\text { proposta a partir do } \\
\text { questionamento } \\
\text { reconstrutivo }\end{array}$ & $\begin{array}{l}10 \text { - Escrita do planejamento } \\
\text { com as atividades a serem } \\
\text { desenvolvidas no contexto da } \\
\text { educação básica. }\end{array}$ & $\begin{array}{l}10 \text { - Organizar a proposta } \\
\text { que possibilite responder ao } \\
\text { questionamento reconstru- } \\
\text { tivo, considerando as } \\
\text { estratégias estudadas ao } \\
\text { longo do curso. }\end{array}$ \\
\hline 8 & $\begin{array}{l}\text { Crítica ao planejamento } \\
\text { pelos pares - reelaboração } \\
\text { da proposta }\end{array}$ & $\begin{array}{l}11 \text { - Retomada do } \\
\text { planejamento a partir da } \\
\text { crítica construída pelos } \\
\text { pares. }\end{array}$ & $\begin{array}{l}11 \text { - Promover o diálogo } \\
\text { crítico entre os pares, a } \\
\text { capacidade de análise e a } \\
\text { possibilidade de aperfei- } \\
\text { çoamento das propostas } \\
\text { apresentadas. }\end{array}$ \\
\hline 9 & $\begin{array}{l}\text { Elaboração do relatório com } \\
\text { os resultados da utilização da } \\
\text { proposta em sala de aula }\end{array}$ & $\begin{array}{l}12 \text { - Escrita do "Relatório } \\
\text { Final" com todas as etapas, } \\
\text { considerando o questiona- } \\
\text { mento reconstrutivo, objetivos, } \\
\text { o cronograma e detalhamento } \\
\text { das atividades e análise dos } \\
\text { resultados conquistados com o } \\
\text { desenvolvimento da proposta. }\end{array}$ & $\begin{array}{l}12 \text { - Fomentar a escrita, a } \\
\text { capacidade de síntese, a } \\
\text { reflexão sobre as ações } \\
\text { realizadas e a avaliação do } \\
\text { processo como um todo. }\end{array}$ \\
\hline 10 & $\begin{array}{l}\text { Fechamento com avaliação } \\
\text { do percurso do curso pelos } \\
\text { professores formadores e } \\
\text { professores em formação. }\end{array}$ & $\begin{array}{l}13 \text { - Avaliação do curso de } \\
\text { formação continuada por } \\
\text { meio de um questionário. }\end{array}$ & $\begin{array}{l}13 \text { - Avaliar as conquistas e } \\
\text { as fragilidades da proposta } \\
\text { desenvolvida para a } \\
\text { formação continuada de } \\
\text { professores de ciências. }\end{array}$ \\
\hline
\end{tabular}

Fonte: Autores. 
Grande parte das atividades foram planejadas considerando as etapas que envolvem o questionamento reconstrutivo, a argumentação, a crítica e a validação (GALIAZZI; MORAES, 2002). Na segunda parte de cada encontro, os professores precisavam pensar sobre alguma situação específica, principalmente sobre a própria realidade de trabalho, e exercitar a autoria na proposição de escritas reflexivas a partir do que foi estudado teoricamente.

No educar pela pesquisa, conduzindo ao aprender a aprender, faz-se do escrever maneira de pensar, isto é, pelo exercício da escrita aprende-se a pensar por mão própria e nisto está um entendimento inovador. A lógica tradicional inverte-se. Do pensar para escrever desenvolvese o escrever para pensar. A produção textual é modo de organizar a aprendizagem, a reflexão e o próprio pensamento (GALIAZZI; MORAES, 2002, p. 240).

Logo nos dois primeiros encontros do curso, os professores participantes tiveram que estruturar e reestruturar um questionamento desencadeador para a elaboração de sua própria proposta de ensino. Assim, ao longo da formação, os professores realizaram muitas atividades relacionadas à elaboração textual com o objetivo de construir o seu próprio material, que foi o produto ao final do curso. A prática de elaboração textual durante o curso, no início, trouxe um pouco de estranhamento aos participantes, porém, com o passar dos encontros, tornou-se uma atividade aceita e valorizada pelo grupo.

Diante do detalhamento das etapas realizadas durante o curso, apresentado no quadro 1 , dois momentos são destacados no presente trabalho. $O$ primeiro diz respeito à formulação do questionamento inicial (encontros 1 e 2), e o segundo está relacionado ao encontro 8 , em que um professor em formação analisou criticamente a proposta de ensino elaborada por um colega da turma. Assim, os resultados serão apresentados em dois blocos: 1) análise dos resultados obtidos na elaboração e reelaboração do questionamento e 2) análise dos apontamentos críticos às propostas de ensino, feitos pelos colegas professores da turma. Esse recorte busca dar ênfase às construções elaboradas pelos professores participantes em relação aos fundamentos do educar pela pesquisa, que foram adaptados de modo a serem utilizados durante o curso.

Para a análise, os materiais produzidos pelos professores durante os encontros foram categorizados por meio da análise de conteúdo (BARDIN, 2011), formando o corpus da análise. O conteúdo qualitativo permitiu verificar a singularidade dos elementos apresentados, considerando-se as variações identificadas nas produções elaboradas em cada atividade por todo o grupo de professores, sem a determinação prévia de categorias.

Os materiais organizados de forma escrita foram isolados (inventário) e arranjados como unidades de registro de modo que os enfoques apresentados pelos professores, em cada atividade, pudessem ser identificados. A partir disso, foram propostas categorias que permitiram um diagnóstico das características específicas do caso em estudo, mostrando as especificidades nas construções elaboradas pelos professores em função da proposição fundamentada no educar pela pesquisa. 


\section{Resultados e Discussões}

"O questionamento reconstrutivo pode ser considerado como o primeiro momento da educação pela pesquisa. Quem questiona um conhecimento ou uma prática existente precisa trazer uma proposta nova que substitua aqueles elementos questionados" (GALIAZZI; MORAES, 2002, p. 243). Essa foi a proposta apresentada aos professores do curso, motivandoos a pensar em situações da sua prática docente, principalmente um aspecto que eles gostariam de melhorar ou modificar. A partir desse questionamento, as atividades dos encontros seguintes do curso foram sempre vinculadas à progressiva elaboração de um material que pudesse responder ao questionamento, bem como trazer suporte de execução em suas ações docentes.

$\mathrm{Na}$ análise dos relatos dos professores no primeiro encontro, que tinha como objetivo a elaboração do questionamento desencadeador, foi possível observar que a maioria $(54,2 \%)$ apresentou situações que não se caracterizavam como um questionamento (grupo 1) e 45,8\% dos professores elaboraram o questionamento solicitado (grupo 2).

O quadro a seguir (quadro 2) organiza as principais respostas apresentadas pelos professores, conforme os grupos mencionados acima.

Quadro 2 - Grupos correspondentes às respostas dos professores na elaboração do questionamento

\begin{tabular}{|l|l|}
\hline G1 - Não elaboraram um questionamento & \multicolumn{1}{|c|}{ G2 - Elaboraram um questionamento } \\
\hline Subcategoria G1a: & Subcategoria G2a: \\
Apresentação do contexto de trabalho & Questionamento sobre "como" utilizar uma \\
Subcategoria G1b: & metodologia para a melhoria das aulas \\
Explicitação dos objetivos a serem alcançados com & $\begin{array}{l}\text { Subcategoria G2b: } \\
\text { a formação }\end{array}$ \\
Subcategoria G1c: & Questionamento a ser apresentado aos estudantes \\
Exposição de uma proposta a ser desenvolvida & \\
\hline
\end{tabular}

Fonte: Autores.

Em relação ao grupo de professores que não elaboraram um questionamento (G1), foi possível observar que ao invés de proporem um questionamento desencadeador, apresentaram informações sobre o seu contexto de trabalho (G1a), por exemplo:

P20 - Meus alunos têm poucos hábitos de estudo, têm acesso à internet e apresentam dificuldades em programas básicos, mas facilidade na produção de vídeos.

Nesse grupo (G1), muitos professores explicitaram os objetivos a serem alcançados com a formação continuada (G1b), por exemplo:

P7 - Busco junto a essa formação, construir ou desenvolver junto ao grupo ferramentas e mecanismos para auxiliar meus alunos a interpretar e analisar informações provenientes de gráficos e tabelas, como extrair as informações contidas nestes e trabalhar isso de maneira que seja significativa. 
Ainda no G1, alguns professores mostraram já ter propostas planejadas, ou seja, ao invés de pensar em uma situação problema de seu cotidiano, mostraram ter um planejamento já definido a ser desenvolvido (G1c), conforme o exemplo a seguir:

P1 - Este semestre vou ministrar aulas de biologia para uma turma de um curso técnico em produção de áudio e vídeo, assim, a ideia é fazer um misto de sala de aula invertida com aprendizagem baseada em projetos e terminar com uma produção de vídeo.

Por outro lado, os resultados do grupo de professores que apresentaram um questionamento desencadeador (G2) na atividade realizada no primeiro encontro do curso possibilitaram a separação em duas categorias (quadro 2), associados a uma metodologia (G2a) e associados a possíveis questionamentos frequentes dos estudantes (G2b). Os parágrafos a seguir exemplificam essas duas subcategorias.

Subcategoria G2a:

P4 - De que forma eu poderia unir aprendizagem baseada em problemas às aulas práticas de biologia, de modo que instigue o aluno a relacionar o observado em aula ao seu cotidiano?

P9 - Como posso trabalhar o conteúdo de Tabela periódica, de forma diferente e atraente, oferecendo significado para os alunos do nono ano?

Subcategoria G2b:

P13 - Onde são encontrados os elementos da tabela periódica? O que produzimos a partir deles?

Os resultados mostram que a maior parte dos professores não compreendeu a proposta do questionamento reconstrutivo, mesmo dentre os que formularam. Percebeu-se que uma parte pensou em uma pergunta a ser apresentada para os estudantes (G2b) e não em algo da sua prática que poderia ser problematizado. Esses resultados indicam que a apresentação da proposta poderia ter acontecido de forma mais detalhada, no primeiro encontro, permitindo que os professores formadores organizassem a reelaboração do questionamento como atividade do encontro seguinte (segundo encontro, quadro 1), com maior número de exemplos e informações para que todos pudessem compartilhar suas dúvidas e objetivos. Entende-se que propostas de formação continuada, em que o contexto dos professores, suas dificuldades e desafios são considerados, consentem que as ações possam contribuir mais diretamente na sua prática e nos processos de reflexão. Isso foi vivenciado tanto pelos professores formadores quanto pelos professores em formação, pois, buscou-se construir o caminho mais adequado para o grupo no decorrer do caminho, sem definições rígidas e inflexíveis. Conforme Demo (2015, p. 9), “[...] não é possível sair da condição de objeto (massa de manobra), sem formar consciência crítica desta situação e contestá-la com iniciativa própria, fazendo deste questionamento o caminho para a mudança". 
Também cabe ressaltar que os resultados do primeiro encontro mostraram que a maioria dos professores não tinha experiência anterior de formação desenvolvida com metodologias em que um problema do contexto da prática profissional fosse foco de análise no processo de formação.

\section{A Reelaboração do questionamento construtivo}

De acordo com Galiazzi e Moraes (2002, p. 250), “[...] por ser essencialmente um processo de questionamento e argumentação, o educar pela pesquisa constitui-se num exercício permanente de reflexão sobre a prática". Assim, é fundamental que o questionamento reconstrutivo seja elaborado a partir da reflexão sobre as próprias vivências dos professores, sobre como compreendem sua prática e quais aspectos dessa prática lhes trazem angústias e insatisfação, de modo que a formação possa auxiliar na proposição de alternativas possíveis.

Para tanto, no segundo encontro, os professores formadores fizeram uma discussão sobre a função do questionamento como desencadeador de todo o percurso da formação continuada. A partir disso, os professores em formação tiveram a oportunidade de repensar e reescrever seus questionamentos, de modo que todos os presentes conseguiram definir qual o problema que seria foco do planejamento a ser elaborado, contemplando objetivos gerais e específicos no exercício da escrita.

A análise dos resultados obtidos permitiu a organização dos questionamentos em 3 categorias, de acordo com o foco apresentado, citados no quadro 3.

Quadro 3 - Categorias dos questionamentos reelaborados pelos professores.

\begin{tabular}{|l|l|l|}
\hline \multicolumn{3}{|c|}{ Categorias dos Questionamentos Reelaborados (Q) } \\
\hline $\begin{array}{l}\text { 1 - Utilizar uma determinada } \\
\text { metodologia (Q1) }\end{array}$ & $\begin{array}{l}\text { 2- Chamar a atenção dos } \\
\text { estudantes (Q2) }\end{array}$ & 3 - Integrar conteúdos (Q3) \\
\hline
\end{tabular}

Fonte: Autores.

Uma parte dos professores mostrou estar preocupada com o "como" planejar e desenvolver metodologias para abordar assuntos que fazem parte do currículo das disciplinas de ciências, química e/ou biologia (Q1). Esses relatos inferem que os professores estão motivados em modificar suas práticas docentes em relação ao tema relatado. Observa-se isso nos exemplos a seguir: 
P13 e P3 - Como podemos desenvolver uma metodologia de ensino de ciências sobre nutrientes?

P19 - Como desenvolver novas práticas pedagógicas sobre a temática das doenças transmitidas pela água, utilizando novas metodologias e instrumentos?

Segundo Demo (2015), entre educação e pesquisa há um trajeto coincidente, em que ambas condenam a cópia, porque ela consagra a subalternidade. Assim, a educação reage contra o mero ensino copiado para copiar, privilegiando o saber pensar e o aprender a aprender. Percebe-se esta vontade no grupo de professores em formação, uma vontade de transformar as aulas em experiência criativa, de aprendizagem mútua.

Um grupo de professores apresentou questionamentos com foco no aluno enquanto sujeito que precisa se sentir motivado para aprender (Q2). Os professores indicaram a vontade de despertar o interesse, tornar as aulas mais atrativas, considerar a realidade dos estudantes e torná-los mais engajados nas propostas desenvolvidas em aula. Como exemplificado:

P16 - Como abordar os conteúdos de estequiometria, envolvendo impurezas e rendimento de reação, mais próximo da realidade do aluno e tornar mais fácil para o entendimento do estudante?

P17 - Como fazer com que os alunos sejam multiplicadores de ações favoráveis à coleta seletiva de lixo e, ao mesmo tempo, que os mesmos também aprendam a cuidar mais do mundo que o cerca?

Houve ainda um terceiro grupo de questionamentos em que os professores indicaram a necessidade de planejar o estudo de determinados conceitos de forma integrada com outros temas ou conhecimentos importantes para o desenvolvimento dos estudantes (Q3). Segue um exemplo:

P15 - Como trabalhar o Sistema digestório com os oitavos anos, integrando nutrição e saúde?

Destaca-se que, em todas as propostas apresentadas na reconstrução do questionamento, os professores mostraram-se motivados pela elaboração de uma proposta que resultasse em uma experiência nova, possível de ser desenvolvida no contexto das instituições de ensino em que atuam, e capaz de trazer contribuições para o exercício da docência.

\section{Bloco 2 - Crítica à proposta dos pares}

Como uma possibilidade de análise dos planejamentos elaborados pelos colegas para aperfeiçoamento após a crítica, antes da aplicação no contexto da sala de aula, 
os professores em formação acessaram a proposta a ser desenvolvida por um dos colegas (planejamento por escrito) e, tendo por base questões ${ }^{1}$ elaboradas pelos professores formadores, organizaram críticas também por escrito.

Segundo Galiazzi e Moraes (2002, p. 244), “[...] o educar pela pesquisa implica na necessidade de comunicar os argumentos, elaborados a partir dos questionamentos, a outros sujeitos do discurso". Os professores em formação realizaram outros exercícios de crítica ao analisarem a proposta pedagógica de um objeto educacional para o ensino de conceitos de ciências e, também, ao analisarem experiências desenvolvidas pelos professores formadores. Todavia, a crítica às propostas dos colegas permitiu a colaboração entre os participantes do curso, objetivando a organização de propostas de maior qualidade. Assim, ao desenvolverem as propostas em sala de aula, para validação do que foi construído, os professores puderam também avaliar a importância das sugestões dos colegas, para além dos subsídios teóricos utilizados durante o processo.

A análise da crítica realizada pelos professores em formação possibilitou a verificação de 4 categorias (quadro 4), segundo o tipo de crítica realizada.

Quadro 4 - Classificação, em categorias, dos pareceres apresentados pelos professores às propostas construídas pelos colegas do curso.

\begin{tabular}{|l|l|l|l|}
\hline \multicolumn{4}{|c|}{ Categorias (C) } \\
\hline $\begin{array}{l}\text { 1 - A ausência de } \\
\text { elementos importantes } \\
\text { na descrição da proposta } \\
\text { (C1) }\end{array}$ & $\begin{array}{l}\text { 2 - Sugestões sobre o } \\
\text { conteúdo (C2) }\end{array}$ & $\begin{array}{l}\text { 3 - Falta de clareza nas } \\
\text { atividades apresentadas } \\
\text { (C3) }\end{array}$ & $\begin{array}{l}\text { 4 - Melhoria de aspectos } \\
\text { metodológicos (C4) }\end{array}$ \\
\hline
\end{tabular}

Fonte: Autores.

Percebeu-se que alguns professores em formação indicaram aos colegas a ausência de algum elemento importante na descrição da proposta, situação que, segundo eles, dificultou a compreensão do todo no planejamento em análise $(\mathrm{C} 1)$. Foram apontadas, nessa categoria, a falta de atividades avaliativas, a ausência de detalhamento na proposição de atividades, com delimitação do tempo para cada etapa ou de fundamentação teórica na introdução do planejamento. As críticas dos professores 5 e 17 exemplificam essa categoria:

P5 - No planejamento não foi possível ver o texto ou as estórias trabalhadas, mas pelo que foi acompanhado ao longo do curso e baseado em alguns autores, o conto de estórias pode contribuir para conexão conceitos/alunos. No planejamento aparecem aulas expositivas e dialogadas, que têm sua importância dentro do trabalho, apenas acho que faltou especificar as formas de avaliações (se houveram) nestas aulas mais teóricas. 
P17 - No item "ideias iniciais" acho que faltou um pouco de referencial teórico para embasar o porquê das atividades serem realizadas desta maneira. Além de situar o leitor na turma em que o planejamento será aplicado.

Alguns professores (C2) avaliaram aspectos relacionados ao conteúdo abordado (C2), propondo alterações para qualificar a exploração de determinados conceitos, sugerindo a proposição de experimentos ou a ampliação do enfoque, como nos exemplos abaixo:

P20 - Acho que poderias não se deter aos pontos de fusão e ebulição somente da água. Talvez um comparativo com outras substâncias ajude a compreender os gráficos e as tabelas quando há diversas informações[...]. Sugiro incluir outras substâncias para que eles possam comparar o estado fisico de outras substâncias à mesma temperatura. Consequentemente a atividade será mais rica em informações para que eles debatam as construções e descobertas.

P7 - Os alunos conhecem o conceito de densidade? Os alunos conseguem distinguir os distintos impactos ambientais ocasionados pelo derramamento de petróleo? Penso que uma coisa simples e que poderia dar a ideia de separação de misturas e associação de densidade seria tentar recriar com eles a mistura "água do mar e óleo" as misturas da água com o sal e do óleo. Sempre é enriquecedor quando eles conseguem criar e desta criação ou experimentação eles conseguem formular seus conceitos e deste ponto de partida estudar sobre os impactos ambientais sofridos nesta situação em especifico.

$\mathrm{Na}$ categoria "falta de clareza nas atividades apresentadas" (C3), as críticas estão relacionadas às propostas em que os professores avaliaram que é necessário que o autor tenha maior cuidado na escrita, para que a proposta fique mais clara, ou seja, os elementos da proposta estão presentes, mas não estão descritos com qualidade suficiente para serem compreendidos pelo leitor. Como exemplos:

P1 - Não ficou claro em que momento as atividades serão desenvolvidas[...]. A entrega de questionário para avaliação dos conhecimentos prévios sobre respiração e órgãos envolvidos na respiração (aula anterior), deveria estar como atividade 1. As demais atividades me pareceram claras apenas fiquei em dúvida como se dará a pesquisa dos termos, se na internet, nos livros da biblioteca ou em ambos. Quanto a entrega dos apontamentos, ela se dará por grupo de forma digital ou em papel?

P18 - Não percebi no detalhamento das atividades algum momento onde os alunos pesquisem em casa. Na atividade está relatado que "iremos conhecer, através de documentos e material de divulgação[...]". No meu entendimento quem trará este material será o professor. O aluno receberá todo o material pronto? A parte dos alunos é criar hipóteses e chegar a conclusões perante o material trazido somente pelo professor?

Em relação aos apontamentos sobre os aspectos metodológicos (C4), os professores problematizaram a metodologia utilizada para dar conta dos objetivos indicados nos 
planejamentos. Os professores puderam explicitar suas análises a respeito das estratégias que os colegas escolheram para a aplicação de suas propostas. São exemplos:

P22 - No questionamento inicial a professora quer desenvolver práticas pedagógicas, utilizando novas metodologias e instrumentos, mas deveria utilizar outras formas de pesquisa através de vídeos ou experimentos. Ela quer novas metodologias, mas utilizou as mesmas práticas pedagógicas: internet, livros, tabelas. Na exposição das ideias iniciais, já foram previamente abordados os assuntos tratados no objetivo geral, na atividade, a professora deveria buscar outra alternativa para avaliar seus alunos, visto que, na internet é possivel buscar o quadro resumo pronto.

P11 - As atividades desenvolvidas e os conteúdos abordados talvez ficassem melhor explicados com exemplos, um vídeo sobre o assunto no primeiro momento após pesquisas de vocabulário desconhecido e dúvidas.

Entende-se que os resultados mostram a riqueza das produções elaboradas pelos professores em formação, explicitando a importância de atividades em que o grupo pode exercitar a crítica construtiva ao trabalho do colega, possibilitando um trabalho conjunto, colaborativo. Para Galiazzi e Moraes (2002, p. 241), "[...] dando-se por meio do diálogo e crítica constantes, a avaliação passa a ser função não só do professor, mas de todos os participantes. Avalia-se para ajudar o outro a aperfeiçoar seus questionamentos, produções e argumentações." Desse modo, ao avaliar o trabalho dos colegas, os professores em formação também estavam refletindo sobre suas propostas individuais, ampliando seus olhares a respeito das possibilidades de atuação. Ao final da atividade, alguns professores solicitaram aos colegas a disponibilização das propostas para que todos pudessem tê-las como fonte de consulta para adaptarem às suas realidades. Todos aqueles que se sentiram à vontade disponibilizaram seus relatórios finais em pdf para os colegas acessarem como fonte de consulta.

\section{Considerações finais}

A análise dos resultados apresentados no trabalho permite afirmar que, mesmo com uma carga horária reduzida, um curso de extensão para formação continuada pode constituir-se como uma oportunidade para professores refletirem a respeito de suas práticas, bem como de novas possibilidades metodológicas a serem adaptadas e desenvolvidas no contexto da educação básica. Salienta-se a importância da escolha por aproveitar o tempo da formação, durante os encontros, tanto para o estudo de elementos teóricos de distintas metodologias para o ensino e a aprendizagem nas aulas de ciências, quanto para a elaboração individual e coletiva, de modo que os professores em formação puderam ter um espaço e tempo para a construção de suas propostas. Os momentos coletivos proporcionaram uma ampliação no conhecimento de ferramentas que podem ser associadas às aulas. 
Ao elaborarem e reelaborarem o questionamento reconstrutivo, os professores em formação mostraram-se motivados em conhecer e utilizar metodologias que tornem as aulas de ciências um espaço interessante para os estudantes, integrando diferentes áreas do conhecimento, materiais pedagógicos, estratégias de ensino e também abordando temas do contexto da comunidade escolar. Destaca-se a constante preocupação com o processo de aprendizagem dos estudantes, principalmente em relação a conteúdos tradicionalmente citados como de difícil compreensão ou com pouca variedade de ferramentas metodológicas, para os quais os professores sentem-se desafiados no momento de planejar e desenvolver as aulas.

O formato do curso, com encontros periódicos, utilização da plataforma Moodle e de ferramentas digitais, também proporcionou aos professores participantes uma autoanálise, aperfeiçoamento e ampliação de possibilidades que podem ser aplicadas e adaptadas em sua atuação profissional, levando em consideração as características dos educandos, realidade escolar e da comunidade atendida.

Salienta-se que a utilização dos pressupostos do educar pela pesquisa, como fundamento para a estruturação da formação continuada, permitiu que os professores se tornassem autores das próprias propostas. Dessa forma, assumiram a responsabilidade pela escolha e elaboração de argumentos a partir da análise do seu contexto de trabalho, dos problemas, das dificuldades vivenciadas e dos desafios apresentados pelos professores formadores. Isso oportunizou que novos caminhos fossem construídos, mesmo que de forma modesta, em ações pontuais, mas com consciência e comprometimento necessários para iniciarem novas formas de pensar e agir no contexto das instituições de ensino em que são docentes.

\section{Referências}

BARDIN, L. Análise de Conteúdo. Edições 70, LDA: Lisboa, 2011.

CAMARGO, A. N. B. A influência da pergunta do aluno na aprendizagem: o questionamento na sala de aula de química e o educar pela pesquisa. 2013. 109 f. Dissertação (Mestrado em Educação em Ciências e Matemática) - PUCRS, Porto Alegre, 2013. Disponível em: http://repositorio.pucrs.br/dspace/bitstream/10923/7400/1/000470756-Texto\%2bCompleto0.pdf. Acesso em: 20 nov. 2019.

DEMO, p. Pesquisa. Princípio científico e educativo. 14 ed. São Paulo: Cortez, 2011.

DEMO, P. Educar pela Pesquisa. 10 ed. Campinas: Autores Associados, Ltda, 2015. 
GALIAZZI, M.C.; MORAES, R. Educação pela Pesquisa como modo, tempo e espaço de qualificação da formação de professores de ciências. Ciência \& Educação. Vol. 8, n.2, p. 237, 2002.

LÜDKE, M.; \& ANDRÉ, M. E. D. A. Pesquisa em educação: abordagens qualitativas. 2 ed. São Paulo: EPU, 2017.

MEDEIROS, L. P. ; SCANDORIEIRO, S. ; KIMURA, A. H. ; MARQUES, L. A. ; GONCALVES, G. D. ; ARANOME, A. M. F. ; NAKAZATO, G. ; MOREY, ALEXANDRE T. ; KOBAYASHI, R. K. T. . Reconhecendo a Microbiologia no nosso dia-a-dia pelo método PBL por estudantes do ensino médio. Luminária, v. 19, p. 34-43, 2017.

POZO, J.I. A solução de problemas: Aprender a resolver, resolver para aprender. Porto Alegre: Artmed, 1998.

POZO, J. I.; GÓMEZ CRESPO, M.A. A aprendizagem e o ensino de ciências. Do conhecimento cotidiano ao conhecimento científico. 5 ed. Porto Alegre: Artmed, 2009.

SAKAI, M. H.; LIMA, G.Z. PBL: uma visão geral do método. Olho Mágico, Londrina, v. 2, n. 5/6, n. esp., 1996.

SCANDORIEIRO, S. ; KIMURA, A. H. ; MEDEIROS, L. P. ; MARQUES, L. A. ; ARANOME, A. M. F. ; NAKAZATO, G. ; KOBAYASHI, RENATA KATSUKO TAKAYAMA ; GONCALVES, G. D. ; MOREY, ALEXANDRE T. Problematização E Práticas De Microbiologia Para Ensino Médio De Escolas Públicas. Experiências Em Ensino De Ciências (UFRGS), v. 13, p. 1, 2018.

SILVA, D. R. O processo criativo na aprendizagem das transformações químicas: uma proposta para estudantes construírem novos conhecimentos na educação básica. Tese de Doutorado, Universidade Federal do Rio Grande do Sul. Instituto de Ciências Básicas da Saúde, Programa de Pós-Graduação em Educação em Ciências: Química da Vida e Saúde, Porto Alegre, 2014.

SILVA, D. R.; DEL PINO, J. C. Como estudantes compreendem uma reação química? Concepções sobre um processo de combustão. Ciências \& Cognição, 19, p. 352, 2014.

SILVA, D.R.; DEL PINO, J. C. Transformações Químicas: As noções dos estudantes ao explicarem fatos de uma história. Pesquisa em Foco (UEMA), v. 21, p. 67, 2016. 
A UTILIZAÇÃO DE PRESSUPOSTOS DO EDUCAR PELA PESQUISA NA ORGANIZAÇÃO E OFERTA DE UM CURSO DE EXTENSÃO PARA A FORMAÇÃO CONTINUADA DE PROFESSORES DE CIÊNCIAS

Bárbara Gonçalves Fenille Velasco, Alexandre Tadachi Morey e Daniela Rodrigues da Silva

YIN, R. K. Estudo de Caso: planejamento e métodos. 5 ed. Porto Alegre: Bookman, 2015.

VELASCO, B.G.F; SILVA, D. R. Formação continuada de professores de ciências:

demandas e possibilidades. In: VIII Salão de Iniciação Científica e Tecnológica, 2018, Canoas. Anais do Salão de Iniciação Científica e Tecnológica e Salão de Extensão do IFRS-Campus Canoas, 2018. Disponível em: $<$ http://enpex.canoas.ifrs.edu.br/enpex/article/view/669>. Acesso em: 22 abril 2020.

${ }^{1}$ Questões: 1) Analise o questionamento inicial apontado pelo autor/professor e opine como as estratégias da proposta estão relacionadas ao questionamento e aos objetivos. Por favor, indique sugestões que você considera importantes para melhorar a proposta avaliada. 2) As atividades estabelecidas no planejamento estão claras? Quais atividades podem ser melhor explicadas? 